genic bacteria in rivers and the identification of trace organic chemicals. The second volume includes accounts of work on oxygen transfer, on the kinetics of aerobic and anacrobic treatment processes, on de-watering of sludges, on sedimentation and on methods of removal of nitrogen, phosphorus and biologically non-degradable organic compounds. The third volume deals largely with the development of rational procedures for the siting of outfalls for the dispersul of sewage, industrial, and radioactive effluents in the sea and with the prediction of the effects of polluting discharges and of natural phenomena on the distribution of dissolved oxygen and nitrogenous compounds in estuaries; the problem of pollution of the sea by oil is also examined.

In the case of each paper presented, at least one formal discussion contribution was prepared by a selected participant, and most of these rank as short papers in their own right; in addition, a good deal of pertinent discussion from the floor has been reported accurately in substance. In general these discussions form a most useful part of the Proceedings and in some cases even outweigh in value the paper under discussion or, by putting its contents into proper perspective, greatly enhance its value.

On the whole, these Proceedings are a chronicle of steady progress rather than revolutionary advance, interspersed, however, with the occasional exceptionally good paper such as one on the theory of the kinetics of gas absorption and one on the prediction of effects of pollution on the condition of water in an estuary.

There is no doubt that anyone concerned with the technical aspects of pollution problems would find a great deal that would be of interest in these volumes, and the research worker in the field should certainly have access to them.

A. L. Downing

\section{PHYSIOLOGY OF MOLLUSCS}

\section{Physiology of Mollusca}

Vol. 1. Edited by Karl M. Wilbur and C. M. Yonge. Pp. xiii +473 . (New York and London: Academic Press, 1964.) 114s. 6d.

$\mathrm{P}$ HYSIOLOGISTS and zoologists alike look forward with interest to new volumes in the Academic Pross series on physiology. The present volume, the first of two on the Physiology of Mollusca, is a wolcome addition to the line and will be a useful work of reference for a long time. However, this volume illustrates the weakness of using a phylum or class as a frame of reference for a physiologist. Too often the reader feels that the most meaningful comparisons would be with members of other phyla rather than with other molluscs. Earlior volumes in the series, such as those on the fishes and the insocts, had a unity, possibly dorived in part from the adaptation of their particular group to one predominant environment. This unity is lacking in the present volumo, and only occasionally, for example in the chapters on sholl and muscle, are there signs of a peculiarly molluscan physiology emerging. This feeling of diffuseness is aggravated by our limited knowledge of molluscan physiology. Two volumes were devoted to each of the groups previously covered in this series and molluscs are also to receive two volumes. To fill them the subject matter has boon widened to include ecology, embryology, comparative anatomy and systematics. Each of these chapters is admirable in its way and the authors havo placed the emphasis on the physiological aspects of their topics, but when the two volumes together are so expensive as to be outside the pockots of many workers on the subject, a single more restricted volume might have beon more valuable. The distribution of topics between the two volumes is rather arbitrary and makes it almost essential to buy them together. Muscles are dealt with in Volume 1, nervous physiology in Volume 2, ionic regulation in Volumo 1, excretion in Volume 2, chromatophores in Volume 1, and pigment in Volume 2.

The book begins with a survey of mollusean strueture and systematics. This is a fine essay in selection and compression by J. E. Morton and C. M. Yonge which readers not too familiar with the molluses will find useful, yet few people interested in the molluses will be without. Morton's excellent little book which covers tho same ground in a more expansive form. In the following chapters G. Newell surveys the ecology of intertidal molluses and W. R. Hunter the ecology of nonmarine forms. Roproduction is a topic in which a poculiarly molluscan physiology may emergo, but V. Fretter and A. Graham's up-to-date survey shows that the subject is still largely in a descriptive phase. The wide variety of forms of hermaphroditism which occurs in the molluses may surpriso some mammalian physiologists. Embryonic development is described by C. P. Raven and this is followed by a largely technical account of the large-scalo culture of marine bivalve larvæ by P. R. Walne.

The elegant geometry and convenient rigidity of the shell make the molluses attractive material for the quantitative study of growth and ageing. Measurement and interpretation of growth are described by $K$. M. Wilbur and G. Owen, who also discuss the influence of metabolism, temperature and nutrition on growth rates. This is followed by an account of the specifically molluscan problem of shell formation by Wilbur, including the metabolism of shell formation, the organic matrix and the various forms in which calcium carbonato can crystallize. There is interesting evidence of a relationship between the nature of the organic matrix and the crystal type. This is a topic which may well throw light on the whole subject of skeleton formation, but, as Wilbur points out, it is curious that detailed information on the composition of the extrapallial fluid from which the shell is deposited is often lacking.

Osmotic and ionic regulation in the molluses is dealt with by J. D. Robertson. One of the determining features of molluscan physiology hero is the high permeability of the body wall which affects both the marino and freshwater forms. Robertson also discusses ionic and osmotic regulation in the tissues, a subject neglected until recently.

The wide variety of muscle conveniently available in the molluses has made the group of unique importance to muscle physiologists. G. Hoyle provides an excellent critical survey of a complicated and disputed field and his article will be of value to all physiologists. Fine structure and biochemical studies are beginning to olucidate the structure of even the slowest molluscan muscles but, in contrast, knowledge of the details of the nervous control of the muscles, is still sadly deficient. Two chapters by Morton describo a variety of minor topics such as bioluminescence and pigment cells, and locomotion. The mobility of the molluscan body has led to a remarkable range of methods of locomotion including both jet propulsion and a less-well-known screw locomotion in some pelagic gastropods. Pelagic molluses have also devoloped two methods for obtaining neutral buoyency. One dopends on their powers of ionic regulation to produce a solution less dense but isosmotic with sea water, the other on the use: of osmotic pressure to abstract water from a rigid shell to produce what is essentially a vacuum. These two phenomena are described by E. J. Denton, who was largely responsiblo for thoir discovory.

The volume is well produced and indexed and few crrors were observed, although $G$. S. Carter did not state that hæmocyanin incroased the oxygen carrying capacity of the blood by 3 por cent (p. 69) but to 3 volumes per cent. The description of the innervation of the anterior byssus retractor muscle (p. 331) would be clearer if the visceral connective, mentioned in the text, were labelled in the diagram and if the cerebropedal connective, also referrerl to in the toxt, were labelled as such and not as the cerebral conneotive.
W. T. W. PoTts 